University of Wollongong

Research Online

Faculty of Engineering - Papers (Archive)

Faculty of Engineering and Information

Sciences

$1-1-2011$

\title{
TiO2(B)@carbon composite nanowires as anode for lithium ion batteries with enhanced reversible capacity and cyclic performance
}

\author{
Zunxian Yang \\ Fuzhou University China \\ Guodong Du \\ University of Wollongong,gd616@uow.edu.au \\ Zaiping Guo \\ University of Wollongong, zguo@uow.edu.au \\ Xuebin Yu \\ xyu@uow.edu.au \\ Zhixin Chen \\ University of Wollongong, zchen@uow.edu.au
}

See next page for additional authors

Follow this and additional works at: https://ro.uow.edu.au/engpapers

Part of the Engineering Commons

https://ro.uow.edu.au/engpapers/1347

\section{Recommended Citation}

Yang, Zunxian; Du, Guodong; Guo, Zaiping; Yu, Xuebin; Chen, Zhixin; Guo, Tailiang; and Liu, Hua-Kun: TiO2(B)@carbon composite nanowires as anode for lithium ion batteries with enhanced reversible capacity and cyclic performance 2011, 8591-8596.

https://ro.uow.edu.au/engpapers/1347

Research Online is the open access institutional repository for the University of Wollongong. For further information contact the UOW Library: research-pubs@uow.edu.au 


\section{Authors}

Zunxian Yang, Guodong Du, Zaiping Guo, Xuebin Yu, Zhixin Chen, Tailiang Guo, and Hua-Kun Liu 


\title{
Journal of
}

\section{Materials Chemistry}

Cite this: J. Mater. Chem., 2011, 21, 8591

www.rsc.org/materials

PAPER

\section{$\mathrm{TiO}_{2}(\mathrm{~B}) @$ carbon composite nanowires as anode for lithium ion batteries with enhanced reversible capacity and cyclic performance $\dagger$}

\author{
Zunxian Yang, ${ }^{* a}$ Guodong Du, ${ }^{b}$ Zaiping Guo, ${ }^{* b c}$ Xuebin Yu, ${ }^{* d}$ Zhixin Chen, ${ }^{c}$ Tailiang Guo ${ }^{a}$ and Huakun Liu ${ }^{b}$ \\ Received 10th November 2010, Accepted 1st April 2011 \\ DOI: 10.1039/c0jm03873c
}

\begin{abstract}
Novel $\mathrm{TiO}_{2}(\mathrm{~B}) @$ carbon composite nanowires were simply prepared by a two-step hydrothermal process with subsequent heat treatment in argon. The nanostructures exhibit the unique feature of having $\mathrm{TiO}_{2}(\mathrm{~B})$ encapsulated inside and an amorphous carbon layer coating the outside. The unique core/shell structure and chemical composition is likely to lead to perfect performance in many applications. In this paper, the results of Li-ion battery testing are presented to demonstrate the superior cyclic performance and rate capability of the $\mathrm{TiO}_{2}(\mathrm{~B}) @$ carbon nanowires. The composite nanowires exhibit a high reversible capacity of $560 \mathrm{mAh} \mathrm{g}^{-1}$ after 100 cycles at the current density of $30 \mathrm{~mA} \mathrm{~g}^{-1}$, and excellent cycling stability and rate capability ( $200 \mathrm{mAh} \mathrm{g}^{-1}$ when cycled at the current density of $750 \mathrm{~mA} \mathrm{~g}^{-1}$ ), indicating that the composite is a promising anode candidate for Li-ion batteries.
\end{abstract}

\section{Introduction}

Carbon has attracted special attention due to its fascinating applications in the field of lithium ion batteries. ${ }^{1-4}$ Although it is one of most commonly used carbonaceous materials in commercial lithium ion batteries, ${ }^{5}$ graphite suffers from its low solid-state diffusion coefficient of lithium, which results in high diffusion resistance during the charge-discharge process and poor $\mathrm{Li}^{+}$storage capacity, ${ }^{6}$ both of which are a challenge to further application in high-performance lithium ion batteries (LIBs). Similarly, most one-dimensional carbonaceous materials, such as carbon nanotubes ${ }^{4}$ and carbon nanofibers, ${ }^{3}$ are subject to extensive capacity fading, ${ }^{7}$ owing to large irreversible capacities stemming from the decomposition of the electrolyte on the electrode during charge/discharge processes. Some others are unsuitable for practical application owing to their complicated chemical and physical synthesis processes. ${ }^{2,8,9}$

Various attempts to improve the $\mathrm{Li}^{+}$storage capacity and cyclability of carbonaceous materials, such as decreasing the particle size, ${ }^{5}$ using porous forms of carbon,,${ }^{3,9}$ coating with hard carbon, ${ }^{10,11}$ and employment of one-dimensional (1D) hybrid carbonaceous materials, ${ }^{12-14}$ have been reported. However, they

${ }^{a}$ Engineering Research Center for Field Emission Display Technology of Ministry of Education, Fuzhou University, Fuzhou 350002, P. R. China. E-mail: yangzunxian@hotmail.com; Fax: +61 24221 5731; Tel: +61 2 42215225

${ }^{b}$ Institute for Superconducting \& Electronic Materials, University of Wollongong, NSW 2522, Australia.E-mail: zguo@uow.edu.au

'School of Mechanical, Materials \& Mechatronics Engineering, University of Wollongong, NSW 2522, Australia

${ }^{d}$ Department of Materials Science, Fudan University, Shanghai 200433, P. R. China. E-mail: yuxuebin@fudan.edu.cn

$\dagger$ Electronic supplementary information (ESI) available. See DOI: $10.1039 / \mathrm{c} 0 \mathrm{jm} 03873 \mathrm{c}$ are still not satisfactory, due to the poor cycling stability, cost of manufacturing, and/or insufficient capacity improvement. Thus, there are still many challenges in simply synthesizing carbonaceous materials that will show high capacity and good cycling stability when employed in the lithium ion battery.

$\mathrm{TiO}_{2}(\mathrm{~B})$ is a metastable monoclinic modification of titanium dioxide. The kinetics of lithium storage in $\mathrm{TiO}_{2}(\mathrm{~B})$ are governed by a pseudo-capacitive faradaic process, which is not limited by solid-state diffusion of $\mathrm{Li}^{+}$. $\mathrm{TiO}_{2}(\mathrm{~B})$ has an open structure with freely accessible channels for $\mathrm{Li}^{+}$-transport perpendicular to the (010) face, which allows easy $\mathrm{Li}^{+}$transport and fast charging of the $\mathrm{TiO}_{2}(\mathrm{~B}) .{ }^{15}$ Therefore, one of the possible strategies to improve the electrochemical properties of carbonaceous materials is to enhance the $\mathrm{Li}^{+}$transport and mechanical performance via introduction of the unique architecture of $\mathrm{TiO}_{2}(\mathrm{~B}) @$ carbon core/ shell nanowires. This combination is of electrochemical interest because it is a novel one-dimensional carbonaceous composite consisting of a $\mathrm{TiO}_{2}(\mathrm{~B})$ nanofiber core, which provides open channels for $\mathrm{Li}^{+}$transport, ${ }^{16,17}$ and a hard carbon shell possessing high $\mathrm{Li}^{+}$capacity. In this paper, we report novel $\mathrm{TiO}_{2}(\mathrm{~B}) @$ carbon core/shell nanowires prepared by a hydrothermal reaction between $\mathrm{NaOH}$ and $\mathrm{TiO}_{2}$ powder, followed by another hydrothermal process in glucose solution and subsequent heat treatment in argon. These $\mathrm{TiO}_{2}(\mathrm{~B}) @$ carbon core/shell nanowires exhibit excellent discharge performance and good cyclability, revealing their potential for application in lithium ion batteries.

\section{Experimental}

Synthesis of $\mathrm{TiO}_{2}(\mathrm{~B}) @$ carbon composite nanowires

Synthesis of $\mathrm{TiO}_{2}(\mathrm{~B}) @$ carbon composite nanowires was performed by a facile two-step hydrothermal process with 
post-treatment. Typically, the precursors, titanate nanowires, were synthesized by adding $4.5 \mathrm{~g} \mathrm{TiO}_{2}$-anatase (99.8\%, Aldrich) to a $15 \mathrm{M}$ aqueous solution of $\mathrm{NaOH}$. After stirring for $1 \mathrm{~h}$, the resulting suspension was transferred to a Teflon-lined autoclave and heated at $150{ }^{\circ} \mathrm{C}$ for $72 \mathrm{~h}$. The product was acid washed, which involved stirring the sample in $0.1 \mathrm{M} \mathrm{HCl}$ solution for $1 \mathrm{~h}$, twice, resulting in the parent $\mathrm{H}_{2} \mathrm{Ti}_{3} \mathrm{O}_{7}$ nanowires. ${ }^{18-21}$ The material was then filtered, repeatedly washed with distilled water, and dried at $80^{\circ} \mathrm{C}$ for $20 \mathrm{~h}$, until $\mathrm{pH} \approx 7$. Subsequently, $0.75 \mathrm{~g}$ of as-prepared $\mathrm{H}_{2} \mathrm{Ti}_{3} \mathrm{O}_{7}$ nanowires was easily dispersed by ultrasonication in $15 \mathrm{ml}$ of $0.8 \mathrm{M}$ aqueous glucose solution. The suspension was transferred to a $30 \mathrm{ml}$ Teflon-lined autoclave, which was then heated in an oven at $180{ }^{\circ} \mathrm{C}$ for at least $4 \mathrm{~h}$. The product was harvested by centrifugation and washed with deionized water and ethanol, respectively, at least five times. After drying at $50{ }^{\circ} \mathrm{C}$, the resulting brown powder was carbonized at $450{ }^{\circ} \mathrm{C}$ for $4 \mathrm{~h}$ under an inert atmosphere. Finally, some black powder was obtained.

\section{Materials characterization}

Thermogravimetric analysis (TGA) of the as-prepared $\mathrm{TiO}_{2}(\mathrm{~B})$ @ carbon composite nanowires was carried out with a TGA/ DSC1 type instrument (METTLER TOLEDO, Switzerland) at a heating rate of $10{ }^{\circ} \mathrm{C} \mathrm{min}{ }^{-1}$ from 25 to $1000{ }^{\circ} \mathrm{C}$ in air. The morphology of the nanowires was evaluated using a JEOL 7500FA field emission scanning electron microscope (FE-SEM, JEOL, Tokyo, Japan) and a JEOL 2011F transmission electron microscope (TEM, JEOL, Tokyo, Japan). Energy dispersive Xray spectroscopy (EDX, JEOL 7500FA) was used to confirm the carbon and $\mathrm{TiO}_{2}$ contents. X-Ray photoelectron spectroscopy (XPS) experiments were carried out on a VG Scientific ESCA$\mathrm{LAB}$ 220IXL instrument using aluminium $\mathrm{K} \alpha \mathrm{X}$-ray radiation during XPS analysis.

\section{Electrochemical characterization}

Electrochemical properties were measured on electrodes prepared by compressing a mixture of as-prepared $\mathrm{TiO}_{2}(\mathrm{~B})$ supported carbon hybrid nanowires, carbon black (Super P, MMM, Belgium), and poly(vinyl difluoride) (PVDF) binder in a weight ratio of $70: 15: 15$ and pasting the mixture onto copper foil. Pure lithium metal foil was used for the counter and reference electrodes. The electrolyte was $\operatorname{LiPF}_{6}(1 \mathrm{M})$ in a mixture of ethylene carbonate (EC) and dimethyl carbonate (DMC) (1: $1 \mathrm{v} / \mathrm{v} ;$ MERCK KgaA, Germany). Coin cells were assembled in a high-purity argon-filled glove box (Mbraun, Unilab, Germany). The galvanostatic method was used to measure the electrochemical capacity of the electrodes at room temperature with a LAND-CT2001A instrument and a chargedischarge current density of $30 \mathrm{~mA} \mathrm{~g}^{-1}$. Rate capability tests of the electrodes were then carried out systematically. The cut-off potentials for charge and discharge were set at 3.0 and $0.01 \mathrm{~V}$ versus $\mathrm{Li}^{+} / \mathrm{Li}$, respectively. To explore the contribution of the $\mathrm{TiO}_{2}$ in the composite to the capacity of electrodes, the cycling performance of electrodes was also investigated with cut-off potentials of 3.0 and $1.0 \mathrm{~V}$ versus $\mathrm{Li}^{+} / \mathrm{Li}$, respectively. Cyclic voltammetry was performed on a ChI660B electrochemical workstation.

\section{Results and discussion}

As shown in Fig. 1, although no sharp characteristic peaks appear, possibly owing to the poor crystallinity of the titanate after the hydrothermal process and the interference of the high carbon content in the $\mathrm{TiO}_{2} @$ carbon nanowires, according to the TGA result (see Supporting Information Fig. S1 $\uparrow$ ), the X-ray diffraction (XRD) patterns of the as-synthesized parent titanate nanowires and $\mathrm{TiO}_{2} @$ carbon hybrid nanowires still reveal that the titanate nanowires are initially $\mathrm{H}_{2} \mathrm{Ti}_{3} \mathrm{O}_{7}$ with a monoclinic structure (JCPDS 47-0561) and undergo a subsequent partial phase transition into $\mathrm{TiO}_{2}$ (B) (JCPDS 74-1940), which comprises the cores of the final TiO $\mathrm{T}_{2} @$ carbon hybrid nanowires, after the glucose-hydrothermal and the argon heat treatment processes. $\mathrm{TiO}_{2}(\mathrm{~B})$ is the main detected phase of $\mathrm{TiO}_{2} @$ carbon hybrid nanowires and belongs to space group $C 2 / m$ (12) with lattice parameters $a=12.1787 \AA, b=3.7412 \AA, c=6.5249 \AA$, and $\beta=107.054^{\circ}$, while $\mathrm{H}_{2} \mathrm{Ti}_{3} \mathrm{O}_{7}$ is the main phase of the parent titanate nanowires belonging to the same space group $C 2 / m$ (12) with lattice parameters $a=16.023 \AA, b=3.749 \AA, c=9.191 \AA$, and $\beta=101.45^{\circ}$. Obviously, the glucose-hydrothermal and following argon heat treatment processes facilitate the conversion from $\mathrm{H}_{2} \mathrm{Ti}_{3} \mathrm{O}_{7}$ phase into $\mathrm{TiO}_{2}(\mathrm{~B})$ with continuous freely accessible parallel channels, ${ }^{18-21}$ which may enhance the $\mathrm{Li}^{+}$ transport in the hybrid nanowire due to the large amount of lithium ions that can be accommodated without any remarkable distortion of structure during charge/discharge cycling.

The field-emission scanning electron microscope (FE-SEM) images clearly show a general view of randomly aligned $\mathrm{H}_{2} \mathrm{Ti}_{3} \mathrm{O}_{7}$ nanowires with diameters of 30-120 nm and lengths extending to a few micrometres (Fig. 2(a,b)). Elemental evaporated gold nanoparticles were used to reduce the electrostatic charging during SEM imaging and can be clearly seen in Fig. 2(b). Furthermore, as shown in Fig. 2(b) and its inset, some $\mathrm{H}_{2} \mathrm{Ti}_{3} \mathrm{O}_{7}$ nanowires have become attached together to form one thicker rod or three-dimensional (3D) microstructure. These microrods and $3 \mathrm{D}$ microstructures that are formed by this process are ultimately responsible for the many mesoporosities or gaps in the electrode materials, which are more favorable to the diffusion of electrolyte. After the glucose-hydrothermal process and

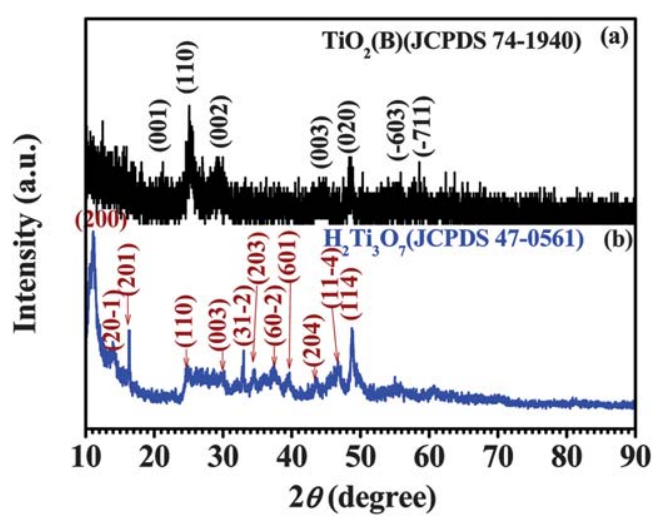

Fig. 1 X-Ray diffraction patterns of as-prepared $\mathrm{H}_{2} \mathrm{Ti}_{3} \mathrm{O}_{7}$ nanowires and $\mathrm{TiO}_{2}(\mathrm{~B}) @$ carbon nanowires: (a) $\mathrm{H}_{2} \mathrm{Ti}_{3} \mathrm{O}_{7}$ nanowires with monoclinic structure (JCPDS 47-0561), (b) $\mathrm{TiO}_{2}$ (B)@carbon nanowires with monoclinic $\mathrm{TiO}_{2}$ (B) core (JCPDS 74-1940), as indexed in the patterns. 


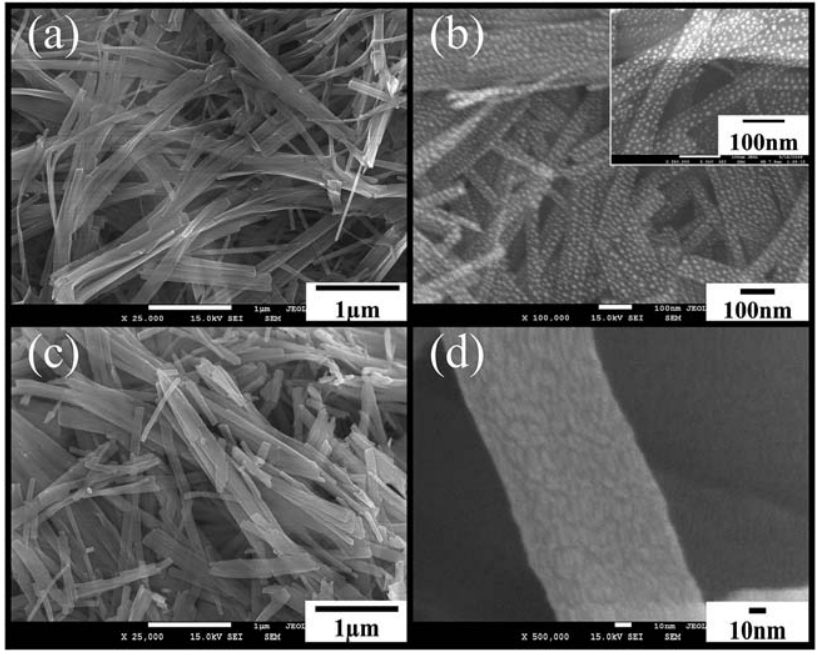

Fig. 2 FE-SEM images of as-synthesized $\mathrm{H}_{2} \mathrm{Ti}_{3} \mathrm{O}_{7}$ nanowires and $\mathrm{TiO}_{2}$ (B)@carbon composite nanowires: (a) $\mathrm{H}_{2} \mathrm{Ti}_{3} \mathrm{O}_{7}$ nanowires, (b) $\mathrm{H}_{2} \mathrm{Ti}_{3} \mathrm{O}_{7}$ nanowires at high magnification and at higher magnification (inset), (c) $\mathrm{TiO}_{2}(\mathrm{~B}) @$ carbon composite nanowires, (d) single $\mathrm{TiO}_{2}(\mathrm{~B})$ @ carbon composite nanowire with porous surface structure. (Gold nanoparticles with grain size of $\sim 5-10 \mathrm{~nm}$ were evaporated on the surface of the $\mathrm{H}_{2} \mathrm{Ti}_{3} \mathrm{O}_{7}$ nanowire samples to reduce electrostatic charging during SEM imaging.)

subsequent heat treatment in argon, as shown in Fig. 2(c,d), these $\mathrm{TiO}_{2}(\mathrm{~B}) @$ carbon nanowires become slightly thicker than the $\mathrm{H}_{2} \mathrm{Ti}_{3} \mathrm{O}_{7}$ nanowires, mainly owing to the encapsulation of $\mathrm{TiO}_{2}$ nanowires in a single thick layer of porous hard carbon (see Fig. 2(d)), which is favorable for both lithium ion storage and $\mathrm{Li}^{+}$ diffusion, possibly stemming from the high specific surface area and the many micropores in this porous carbon.

Transmission electron microscopy (TEM) of the as-synthesized $\mathrm{H}_{2} \mathrm{Ti}_{3} \mathrm{O}_{7}$ nanowires and $\mathrm{TiO}_{2}(\mathrm{~B})$ supported carbon hybrid nanowires provides further structural and morphological information (Fig. 3). Each $\mathrm{H}_{2} \mathrm{Ti}_{3} \mathrm{O}_{7}$ nanowire is a monocrystal with monoclinic structure (Fig. 3(a) and its inset), which is similar to the results of Peng's group. ${ }^{22,23}$ However, due to the random orientation of the $\mathrm{H}_{2} \mathrm{Ti}_{3} \mathrm{O}_{7}$ nanowires, as shown in Fig. 3(b) and the selected area electron diffraction (SAED) pattern in its inset, the $\mathrm{H}_{2} \mathrm{Ti}_{3} \mathrm{O}_{7}$ nanowires are collectively characterized by a polycrystalline ring-shaped SAED pattern. As shown in Fig. 3(c), $\mathrm{TiO}_{2}(\mathrm{~B}) @$ carbon nanowires, inheriting the monoclinic structure characteristics of $\mathrm{H}_{2} \mathrm{Ti}_{3} \mathrm{O}_{7}$ nanowires, also extend along the $[010]_{\mathrm{B}}$ direction. Additionally, there is a very thick layer of carbon on the surface of the $\mathrm{TiO}_{2}(\mathrm{~B})$ nanowires (Fig. 3(c,d)), and this carbon layer forms an effective core/shell 1D structure in conjunction with the $\mathrm{TiO}_{2}(\mathrm{~B})$ nanowire itself. Consequently, the $\mathrm{TiO}_{2}(\mathrm{~B})$ core in the hybrid nanowire provides a continuous channel favorable to $\mathrm{Li}^{+}$transport along the length axis of the nanowire, as well as providing a mechanical support function for the high content of porous carbon, up to $36.67 \%$ by weight (Fig. S2†). This $\mathrm{TiO}_{2}$ (B) support, to some extent, helps to alleviate the stress produced during lithium intercalation/ deintercalation.

As shown in Fig. 4, X-ray photoelectron spectroscopy (XPS) analysis of the $\mathrm{TiO}_{2}(\mathrm{~B}) / \mathrm{C}$ hybrid nanowires was conducted from 0 to $1100 \mathrm{eV}$. Obvious $\mathrm{C} 1 \mathrm{~s}, \mathrm{O} 1 \mathrm{~s}$, and Ti2p peaks were detected,

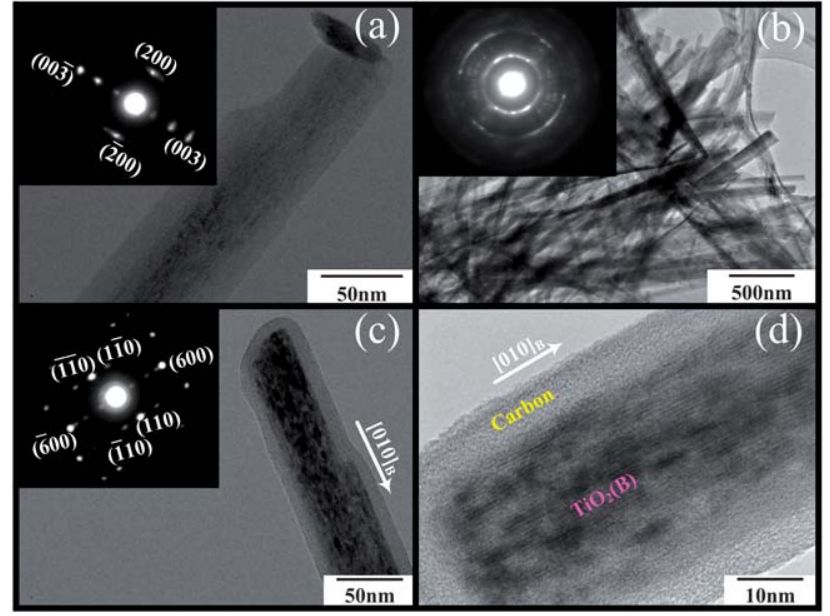

Fig. 3 (a) TEM image and SAED pattern (inset) of single $\mathrm{H}_{2} \mathrm{Ti}_{3} \mathrm{O}_{7}$ nanowire, (b) low-magnification TEM image and SAED pattern (inset) of $\mathrm{H}_{2} \mathrm{Ti}_{3} \mathrm{O}_{7}$ nanowires, (c) TEM image and SAED pattern (inset) of single $\mathrm{TiO}_{2}$ (B)@carbon composite nanowire, (d) HRTEM image of a section of a $\mathrm{TiO}_{2}(\mathrm{~B}) @$ carbon composite nanowire.

and their high-resolution spectra are shown in Fig. 4(a-c), respectively. Fig. 4(a) displays the high resolution spectrum of the $\mathrm{C}$ 1s region of the as-prepared $\mathrm{TiO}_{2}(\mathrm{~B}) / \mathrm{C}$ composite fitted to four peaks, including un-oxidized graphitic carbon. ${ }^{24}$ The two large peaks at $285.0 \mathrm{eV}$ and $285.42 \mathrm{eV}$ are attributed to hydrocarbon, ${ }^{25}$ while the peak at $286.31 \mathrm{eV}$ can be assigned to disordered carbon or oxidant carbon, such as in alcohols. ${ }^{24,25}$ As shown in Fig. 4(b), a portion of the response could come from $\mathrm{TiO}_{2}$, as evidenced by the O1s binding energy (BE) peak at $\sim 530.73 \mathrm{eV},{ }^{24}$ while the peak at $532.31 \mathrm{eV}$ may be due to the $\mathrm{OH}$ radical, adsorbed oxygen, or carbonyl. ${ }^{24,25}$ As for the high $\mathrm{BE}$ peak at $533.92 \mathrm{eV}$, it possibly originates from alcohol or adsorbed $\mathrm{H}_{2} \mathrm{O}$, which is in good accordance with the fitted $\mathrm{Cls}$ peaks. The Ti2p spectrum (Fig. 4(c)) for $\mathrm{TiO}_{2}(\mathrm{~B}) / \mathrm{C}$ comprises two symmetrical peaks with BEs at $459.13 \mathrm{eV}$ and $464.92 \mathrm{eV}$, which are attributable to Ti2p $3 / 2$ and Ti2p $1 / 2$, respectively. The separation between these two peaks is $5.79 \mathrm{eV}$, slightly larger than the energy splitting reported for $\mathrm{TiO}_{2} \cdot{ }^{25,26}$ The cause is possibly the encapsulation of $\mathrm{TiO}_{2}(\mathrm{~B})$ in carbon. From a combination of the XRD, FE-SEM, TEM, and XPS results, it is concluded that the as-synthesized $\mathrm{TiO}_{2}(\mathrm{~B}) / \mathrm{C}$ hybrid nanowires consist of $\mathrm{TiO}_{2}(\mathrm{~B})$ and carbon. After the glucose-hydrothermal process and following heat treatment, the parent $\mathrm{H}_{2} \mathrm{Ti}_{3} \mathrm{O}_{7}$ nanowire ${ }^{18,19}$ is converted into $\mathrm{TiO}_{2}(\mathrm{~B}) / \mathrm{C}$ nanowire, consisting of a $\mathrm{TiO}_{2}(\mathrm{~B})$ crystal core inside a shell of porous hard carbon. In addition, some mesoporosities or gaps are formed by thicker rods (Fig. 2 $(\mathrm{a}-\mathrm{b}))$ and 3D microstructures in the sample, all of which favor the enhancement of the electrochemical performance of the electrode.

The electrochemical performance of the $\mathrm{TiO}_{2}(\mathrm{~B})$ supported carbon hybrid nanowire electrode was systematically investigated (Fig. 5). Cyclic voltammograms $(\mathrm{CVs})$ of $\mathrm{TiO}_{2}(\mathrm{~B})$ supported carbon hybrid nanowires from the first to the fifth cycle at a scan rate of $0.1 \mathrm{mV} \mathrm{s}^{-1}$ in the voltage range of $0.01-3.0 \mathrm{~V}$ were obtained and are presented in Fig. 5(a). The first cycle curve is different from the other ones, possibly owing to the formation of a solid/electrolyte interphase (SEI) on the surface of the active 

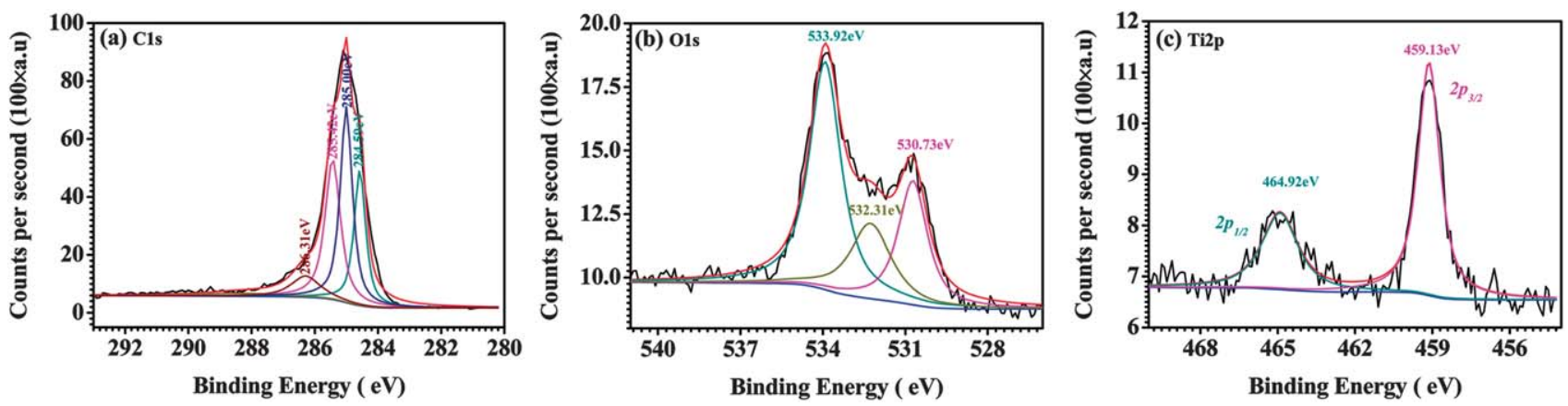

Fig. 4 XPS high-resolution spectra of the (a) C1s, (b) O1s, and (c) Ti2p regions of as-prepared $\mathrm{TiO}_{2}(\mathrm{~B}) @$ carbon composite nanowires.

material. In the first cycle, the cathodic/anodic peak pair at 0.012 $\mathrm{V}$ and $0.14 \mathrm{~V}$ is associated with lithium ion insertion into/ extraction out of the carbon material, while another cathodic/ anodic peak pair at around $0.6 \mathrm{~V}$ suggests the decomposition of solvent, with the decomposition products acting as an SEI on the surface of the carbonaceous shells. ${ }^{27}$ There remain three cathodic/anodic peak pairs at $1.46 \mathrm{~V}$ and $1.57 \mathrm{~V}, 1.55 \mathrm{~V}$ and 1.72 $\mathrm{V}$, and $1.74 \mathrm{~V}$ and $2.0 \mathrm{~V}$ in the first cycle curve, which are possibly attributable to lithium ion insertion into/extraction out of $\mathrm{TiO}_{2}$ in the composite. ${ }^{28}$ Notably, the three cathodic/anodic peak pairs in the first cycle finally merge into one cathodic/anodic peak pair at $1.46 \mathrm{~V}$ and $1.72 \mathrm{~V}$ in the subsequent cycles, probably because of the fundamental variation in the charge transport mechanisms from diffusion-confined charge transport to surface-confined charge transport in this $\mathrm{TiO}_{2}(\mathrm{~B}) / \mathrm{C}$ composite electrode, ${ }^{15,29}$ with the carbon shell being activated by the lithium ion insertion during the first cycle. Additionally, beginning from the $3 \mathrm{rd} \mathrm{CV}$ cycle, the electrode delivers good reversible behavior.

The cycling performance of the $\mathrm{TiO}_{2}(\mathrm{~B}) / \mathrm{C}$ composite electrode from the 1st to the 100th cycle was obtained at a constant current of approximately $30 \mathrm{~mA} \mathrm{~g}{ }^{-1}$, with a cut-off voltage window of $0.01 \mathrm{~V}$ to $3.0 \mathrm{~V}$ (versus $\mathrm{Li} / \mathrm{Li}^{+}$). Fig. 5(b) displays the voltage profiles of electrochemical cells containing these $\mathrm{TiO}_{2}(\mathrm{~B})$ (a) carbon composites at the current density of $30 \mathrm{~mA} \mathrm{~g}^{-1}$. The voltage profiles indicate that the composite electrode has the typical characteristics of a carbon nanomaterial electrode. The first discharge and charge steps deliver a specific capacity of 1278 and $673 \mathrm{mAh} \mathrm{g}^{-1}$, respectively. The large initial capacity loss of the $\mathrm{TiO}_{2}(\mathrm{~B}) @$ carbon composite electrode can be partly attributed to the formation of a thick SEI layer on the electrode surface during the first discharge step $^{30}$ and the high specific surface area of the porous carbon in the $\mathrm{TiO}_{2}(\mathrm{~B}) @$ carbon composite, which
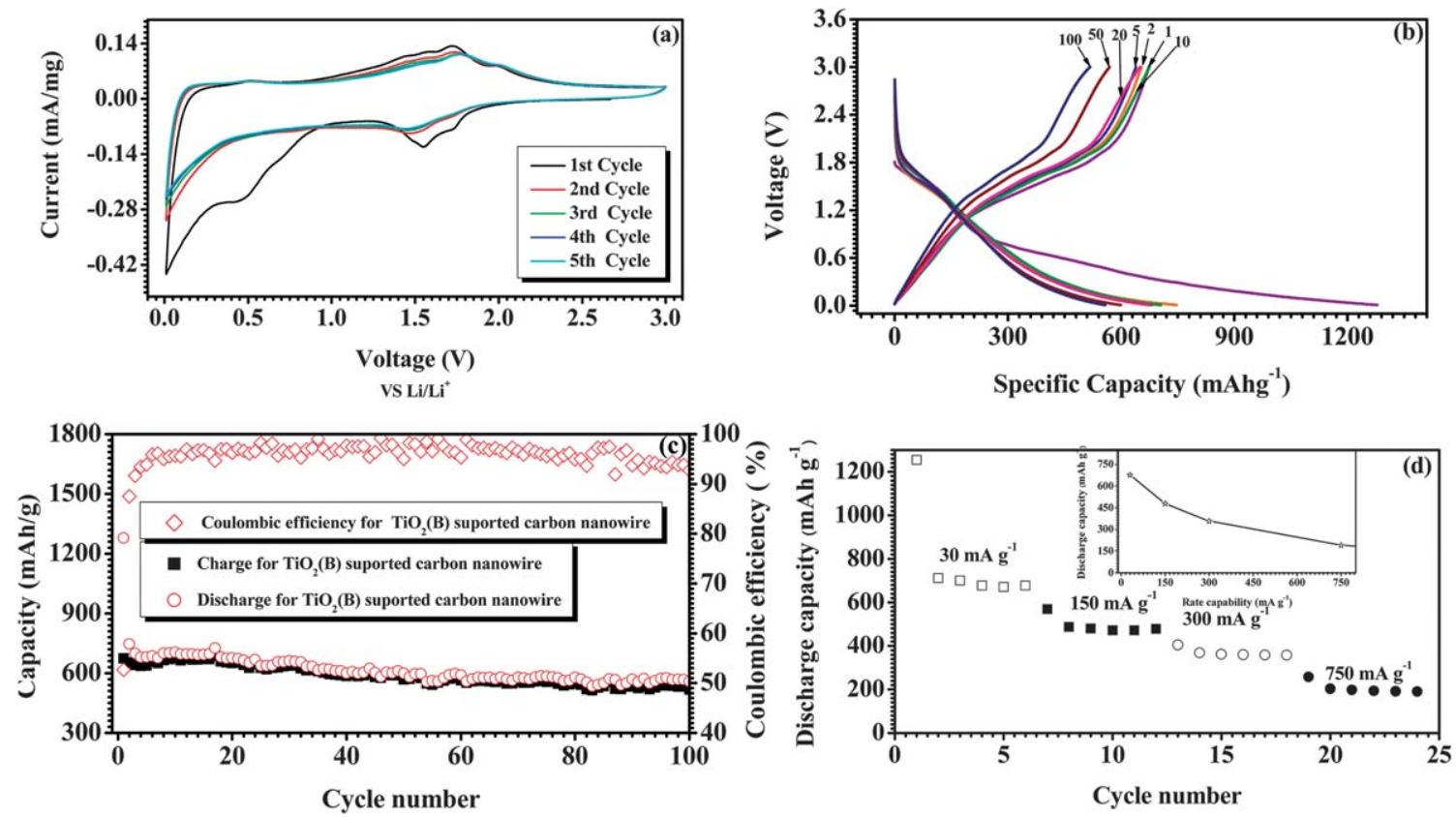

Fig. 5 Electrochemical performance of $\mathrm{TiO}_{2}(\mathrm{~B}) @$ carbon composite nanowire electrode cycled between 0.01 and $3.0 \mathrm{~V} v s . \mathrm{Li}^{+} / \mathrm{Li}:(\mathrm{a}) \mathrm{cyclic}$ voltammograms of $\mathrm{TiO}_{2}(\mathrm{~B}) @$ carbon composite nanowires electrode from the first cycle to the fifth cycle at a scan rate of $0.1 \mathrm{mV} \mathrm{s}^{-1}$ in the voltage range of 0.0 $3.0 \mathrm{~V}$. (b) Voltage profiles for selected cycles of $\mathrm{TiO}_{2}(\mathrm{~B}) @$ carbon composite nanowire composite electrode at the current density of $30 \mathrm{~mA} \mathrm{~g}^{-1}$. (c) Capacity $v s$. cycle number curves from the first cycle to the 100 th cycle for the $\mathrm{TiO}_{2}(\mathrm{~B}) @$ carbon composite nanowires at the current density of $30 \mathrm{~mA} \mathrm{~g}^{-1}$. (d) Discharge capacity of $\mathrm{TiO}_{2}$ (B)@carbon composite nanowire electrode as a function of the discharge rate $\left(30,150,300,750 \mathrm{~mA} \mathrm{~g} \mathrm{~g}^{-1}\right)$; the inset is the discharge capacity-rate capability curve of the $\mathrm{TiO}_{2}(\mathrm{~B}) @$ carbon composite nanowire electrode. 
sacrifices a much higher quantity of irreversible $\mathrm{Li}^{+}$to form the SEI layer as compared with common carbonaceous materials. In addition, the high content of amorphous or disordered carbon in the composite is likely to be partly responsible for the high initial irreversible capacity because of the relatively low carbonization temperature for our sample. Fig. 5(c) shows the curves of discharge capacity versus cycle number for the $\mathrm{TiO}_{2}(\mathrm{~B}) @$ carbon composite electrode at the current density of $30 \mathrm{~mA} \mathrm{~g}^{-1}$. The $\mathrm{TiO}_{2}$ (B)@carbon composite electrode exhibits good cyclic performance and a high reversible specific capacity of over 705 $\mathrm{mAh} \mathrm{g}^{-1}$ in the first 10 cycles, and it maintains a reversible capacity after 100 cycles of approximately $560 \mathrm{mAh} \mathrm{g}^{-1}$. Fig. 5(d) shows the rate capability of the $\mathrm{TiO}_{2}(\mathrm{~B}) @$ carbon composite electrode, which delivers a capacity of about $711 \mathrm{mAh} \mathrm{g}^{-1}$ at the current density of $30 \mathrm{~mA} \mathrm{~g}^{-1}$ after 6 cycles. This value decreases to $482 \mathrm{mAh} \mathrm{g}^{-1}$ at the current density of $150 \mathrm{~mA} \mathrm{~g}^{-1}, 364 \mathrm{mAh}$ $\mathrm{g}^{-1}$ at the current density of $300 \mathrm{~mA} \mathrm{~g}^{-1}$, and $200 \mathrm{mAh} \mathrm{g}^{-1}$ at the current density of $750 \mathrm{~mA} \mathrm{~g}^{-1}$.

The excellent electrochemical performance of the $\mathrm{TiO}_{2}(\mathrm{~B}) / \mathrm{C}$ composite electrode is probably due to its special morphology. As demonstrated in Scheme S1 (Supporting Information $\dagger$ ), the $\mathrm{TiO}_{2}(\mathrm{~B}) @$ carbon composite nanowire, consisting of a $\mathrm{TiO}_{2}(\mathrm{~B})$ crystal core inside a shell of porous hard carbon, possesses one continuous channel along its axis, which is favorable for lithium ion diffusion during charge/discharge processes. For comparison, the cycling performances of the $\mathrm{TiO}_{2}(\mathrm{~B}) / \mathrm{C}$ composite electrode between 1.0 and $3.0 \mathrm{~V}$ vs. $\mathrm{Li}^{+} / \mathrm{Li}$ and the glucosehydrothermal process-derived pure carbon electrode between 0.01 and 3.0 $\mathrm{V} v$ s. $\mathrm{Li}^{+} / \mathrm{Li}$ were also investigated under the same conditions and are shown in Fig. S3 and S4, $\uparrow$ respectively. The capacity portion mainly attributable to the fact that $\mathrm{TiO}_{2}(\mathrm{~B})$ in the composite electrode is very low and fades quickly (see Fig. S3†), as compared with Fig. 5(c). The initial discharge capacity of the pure carbon electrode is as high as $1148.4 \mathrm{mAh}$ $\mathrm{g}^{-1}$, even though the cycling performance of the pure carbon electrode is poor (see Fig. S4†), which is probably attributable to larger particles or agglomerates in the morphology of the pure carbon derived from the direct glucose-hydrothermal method than for the one-dimensional porous carbon on the $\mathrm{TiO}_{2}(\mathrm{~B})$ (a) carbon composite nanowires. Accordingly, it is the onedimensional porous hard carbon shell in this special morphology, not the pure carbon that, to some extent, accelerates diffusion for both electrons and lithium ions, ensuring a high

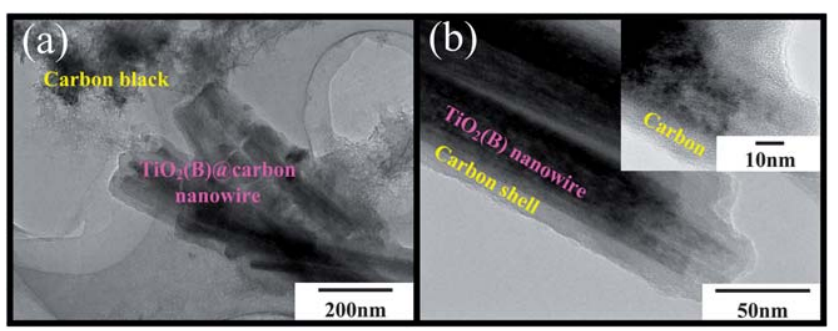

Fig. 6 TEM images of $\mathrm{TiO}_{2}(\mathrm{~B}) @$ carbon composite nanowires after 100 cycles of charge/discharge: (a) low magnification TEM image of sample, (b) higher magnification TEM image of a few $\mathrm{TiO}_{2}(\mathrm{~B}) @$ carbon nanowires; the inset is a HRTEM image of a section of $\mathrm{TiO}_{2}(\mathrm{~B}) @$ carbon nanowire. electrode-electrolyte contact area and eventually making the greater part of the contribution to the capacity. Moreover, the $\mathrm{TiO}_{2}$ (B) core, to some extent, also acts as an effective mechanical support to alleviate the stress produced during lithium intercalation/deintercalation and preserve the one dimensional core/ shell structure even after 100 charge/discharge cycles, as shown in Fig. 6(a,b) and its inset. In addition, the mesoporosities or gaps formed by thicker rods and 3D microstructures (see Fig. 2(c,d)) in the sample are helpful in improving the electrochemical performance of the electrode, possibly because of their contribution to the electrolyte or lithium ion diffusion during charge/ discharge processes.

\section{Conclusions}

In summary, a novel $\mathrm{TiO}_{2}(\mathrm{~B}) / \mathrm{C}$ composite, namely, $\mathrm{TiO}_{2}(\mathrm{~B})$ (a) carbon composite nanowires consisting of a $\mathrm{TiO}_{2}(\mathrm{~B})$ core encapsulated in a porous carbon shell, has been successfully synthesized by an alkali hydrothermal method, followed by another hydrothermal process in glucose solution and subsequent heat treatment in argon. As a potential anode material for lithium ion batteries, this composite displays a high reversible capacity of $560 \mathrm{mAh} \mathrm{g}^{-1}$ after 100 cycles at the current density of $30 \mathrm{~mA} \mathrm{~g}^{-1}$. It also exhibits a reversible discharge capacity of 200 $\mathrm{mAh} \mathrm{g}^{-1}$ when cycled at the current density of $750 \mathrm{~mA} \mathrm{~g}^{-1}$. This novel $\mathrm{TiO}_{2}(\mathrm{~B}) / \mathrm{C}$ composite core/shell structure has one continuous channel along its axis, facilitating lithium ion diffusion and effective mechanical support of the $\mathrm{TiO}_{2}(\mathrm{~B})$ core, alleviating the stress produced during charge/discharge processes. This composite is very promising as a potential anode material for LIBs, even though the composition and structure of these materials require further improvement.

\section{Acknowledgements}

Part of the work was funded by an Australian Research Council (ARC) Linkage Grant (DP1094261), the Postdoctoral Foundation Program of Fuzhou University (BSH-0601), the Natural Science Foundation Program of Fujian Province (2010J01332, A0510011), and the Talent Foundation Program of Fuzhou University. The authors also would like to thank Dr Tania Silver at the University of Wollongong for critical reading of the manuscript and Mr Attard Darren for his great contribution.

\section{References}

1 H. Wang, T. Abe, S. Maruyama, Y. Iriyama, Z. Ogumi and K. Yoshikawa, Adv. Mater., 2005, 17, 2857-2860.

2 I. Lahiri, S.-W. Oh, J. Y. Hwang, S. Cho, Y.-K. Sun, R. Banerjee and W. Choi, ACS Nano, 2010, 4(6), 3440-3446.

3 L. Ji and X. Zhang, Nanotechnology, 2009, 20, 155705 (7 pp.).

4 S. Y. Chew, S. H. Ng, J. Wang, P. Novák, F. Krumeich, S. L. Chou, J. C. and H. K. Liu, Carbon, 2009, 47, 2976-2983.

5 S. Yang, X. Feng, L. Zhi, Q. Cao, J. Maier and K. Müllen, $A d v$. Mater., 2010, 22, 838-842.

6 M. Yoshio, H. Wang and K. Fukuda, Angew. Chem., Int. Ed., 2003, 42, 4203-4206.

7 X. Ji, K. T. Lee and L. F. Nazar, Nat. Mater., 2009, 8, 500-506.

8 L. Ji and X. Zhang, Electrochem. Commun., 2009, 11, 684-687.

9 C. Li, X. Yin, L. Chen, Q. Li and T. Wang, J. Phys. Chem. C, 2009, 113, 13438-13442.

10 M. Yoshio, H. Wang, K. Fukuda, T. Umeno, T. Abe and Z. Ogumi, J. Mater. Chem., 2004, 14, 1754-1758. 
11 B. Tien, M. Xu and J. Liu, Mater. Lett., 2010, 64, 1465-1467.

12 G. Du, C. Zhong, P. Zhang, Z. Guo, Z. Chen and H. Liu, Electrochim. Acta, 2010, 55, 2582-2586.

13 A. L. Mohana Reddy, M. M. Shaijumon, S. R. Gowda and P. M. Ajayan, Nano Lett., 2009, 9(3), 1002-1006.

14 L. Kavana, R. Bacsa, M. Tunckol, P. Serp, S. M. Zakeeruddin, F. L. Formal, M. Zukalova and M. Graetzel, J. Power Sources, 2010, 195, 5360-5369.

15 M. Zukalová, M. Kalbáč, L. Kavan, I. Exnar and M. Graetzel, Chem. Mater., 2005, 17, 1248-1255.

16 G. Armstrong, A. R. Armstrong, P. G. Bruce, P. Reale and B. Scrosati, Adv. Mater., 2006, 18, 2597-2600.

17 A. R. Armstrong, G. Armstrong, J. Canales, R. Garcia and P. G. Bruce, Adv. Mater., 2005, 17(7), 862-865.

18 D. Yang, H. Liu, Z. Zheng, Y. Yuan, J.-c. Zhao, E. R. Waclawik, X. Ke and H. Zhu, J. Am. Chem. Soc., 2009, 131, 17885-17893.

19 W. Li, C. Liu, Y. Zhou, Y. Bai, X. Feng, Z. Yang, L. Lu, X. Lu and K.-Y. Chan, J. Phys. Chem. C, 2008, 112, 20539-20545.

20 T. Beuvier, M. Richard-Plouet and L. Brohan, J. Phys. Chem. C, 2009, 113, 13703-13706.
21 Y. Bai, W. Li, C. Liu, Z. Yang, X. Feng, X. Lu and K.-Y. Chan, J. Mater. Chem., 2009, 19, 7055-7061.

22 G. H. Du, Q. Chen, R. C. Che, Z. Y. Yuan and L. M. Peng, Appl. Phys. Lett., 2001, 79(22), 3702-3704.

23 Q. Chen, G. H. Du, S. Zhang and L. M. Peng, Acta Crystallogr., Sect. B: Struct. Sci., 2002, 58, 587-593.

24 XPS database on Web: http://www.lasurface.com/database/ elementxps.php (November, 2010).

25 N. Ohtsu, N. Masahashi, Y. Mizukoshi and K. Wagatsuma, Langmuir, 2009, 25(19), 11586-11591.

26 S. B. Amor, G. Baud, M. Benmalek, H. Dunlop, R. Frier and M. Jacquet, J. Adhes., 1998, 65, 307-329.

27 T. Fukutsuka, Y. Matsuo, Y. Sugie, A. Takeshi, M. Inaba and Z. Ogumi, Mol. Cryst. Liq. Cryst., 2002, 388, 531-536.

28 L. Kavan, M. Kalbáč, M. Zukalová, I. Exnar, V. Lorenzen, R. Nesper and M. Graetzel, Chem. Mater., 2004, 16, 477-485.

29 K.-W. Nam, S.-B. Ma, W.-S. Yoon, X.-Q. Yang and K.-B. Kim, Electrochem. Commun., 2009, 11, 1166-1169.

30 S. H. Ng, J. Wang, Z. P. Guo, J. Chen, G. X. Wang and H. K. Liu, Electrochim. Acta, 2005, 51, 23-28. 